\section{The safety of moderate hypothermic circulatory arrest with selective cerebral perfusion \\ To The Editor:}

We read with great interest the recent article by Kamiya and colleagues ${ }^{1}$ on the safety of moderate hypothermic circulatory arrest with selective cerebral perfusion (SCP). In a retrospective analysis, the authors divided 377 patients undergoing aortic arch repair with SCP and hypothermic circulatory arrest into 2 groups: group 1 comprised 125 patients with deep lower body circulatory arrest at $20^{\circ} \mathrm{C}$ to $24.9^{\circ} \mathrm{C}$, and group 2 comprised 252 patients with moderate lower body circulatory arrest at $25^{\circ} \mathrm{C}$ to $28^{\circ} \mathrm{C}$. The 2 groups were compared with regard to mortality and neurologic outcomes. A propensity score matching analysis was also undertaken to compensate for the differences in patient characteristics between the 2 groups. The authors found no significant differences between the 2 groups in terms of mortality or morbidity and concluded that moderately hypothermic lower body circulatory arrest during aortic arch repair was safe. The authors are a well-known group of aortic surgeons who deserve credit for undertaking such an important study. The point they wanted to make here is also well taken. However, being a group practicing an essentially similar technique, we could not help bringing up some concerns regarding this article.

First, this is basically a low-flow, lowpressure 2-vessel SCP (the left subclavian artery is mostly occluded) that we also practice at our institution., ${ }^{2,3}$ Basically, at a perfusion flow rate of $10 \mathrm{~mL}$. $\mathrm{kg}^{-1} \cdot \min ^{-1}$, there should not be a big difference between $20^{\circ} \mathrm{C}$ and $28^{\circ} \mathrm{C}$ as far as the cerebral protective effect is concerned. This is especially true for short SCP intervals, as the authors had in this series (22 minutes in both groups). What happens to the spinal cord and visceral organs when the temperature is increased to $28^{\circ} \mathrm{C}$ ? Moreover, do the authors consider the possibility of left vertebrobasi- lar ischemia in certain cases? Have they ever had to switch to a 3-vessel perfusion, especially when they suspected inadequate intracranial arterial communication?

Second, the authors mention that systemic circulatory arrest time is shorter with the island technique of arch vessel reconstruction practiced at their institution. However, we have a different view on this. In our experience we have seen that the arrest time can actually be shorter with the separated graft technique of arch vessel reconstruction, as opposed to that with the island technique. This is because, with the separated graft technique, systemic circulation can be started through the side branch of the arch graft immediately after the completion of distal graft anastomosis. On the other hand, with the island technique, one has to wait for the en bloc repair of the arch vessels to be completed before the systemic circulation can be started.

Third, mean systemic circulatory arrest time was generally short in this series (about 27 minutes). Most patients will be able to tolerate this. However, with an arrest time exceeding 60 minutes in a moderately hypothermic condition of $28^{\circ} \mathrm{C}$, the spinal cord can be at risk of ischemic injury, which is also evident in the results of the present study (paraplegia rate of $18.2 \%$ in these patients as opposed to $0 \%$ in the deep hypothermic arrest group). The authors might want to tell the readers how to bail out when the arrest time becomes unexpectedly long.

Fourth, re-exploration for bleeding was excessively high in both groups: $14 \%$ and $19 \%$ in the moderate hypothermic arrest and deep hypothermic arrest groups, respectively. In our series this rate is less than $2 \%$. What was the reason for such a high rate of re-exploration for bleeding?

Finally, we agree with the authors that the moderately hypothermic lower body arrest can be deemed safe for cases in which its duration is expected to be less than 60 minutes. However, for compli- cated cases, such as acute type A aortic dissection requiring expeditious surgical intervention or in those with a very deeply located distal aortic anastomotic site, where the duration of arrest time can often be unexpectedly long, it might result in a higher rate of stroke, paraplegia, or paraparesis. Further decreasing of the temperature would offer a better protection in these situations.

Teruhisa Kazui, $M D, P h D$

Abul Hasan Muhammad Bashar, MBBS, PhD

First Department of Surgery

Hamamatsu University School of Medicine Hamamatsu City, Japan

\section{References}

1. Kamiya H, Hagl C, Kropivnitskaya I, et al. The safety of moderate hypothermic lower body circulatory arrest with selective cerebral perfusion: a propensity score analysis. $J$ Thorac Cardiovasc Surg. 2007;133:501-9.

2. Kazui T, Washiyama N, Bashar AHM, et al. Total arch replacement using aortic arch branched grafts with the aid of antegrade selective cerebral perfusion. Ann Thorac Surg. 2000;70:3-9.

3. Kazui T, Washiyama N, Bashar AHM, Terada H, Yamashita K, Takinami M. Improved results of atherosclerotic arch aneurysm operations with a refined technique. J Thorac Cardiovasc Surg. 2001;121:491-9. doi:10.1016/j.jtcvs.2007.03.070

\section{Reply to the Editor:}

We are grateful for the opportunity to respond to the letter by Kazui and associates. We appreciate the comments on our recent article reporting moderate hypothermic lower body circulatory arrest with selective cerebral perfusion. ${ }^{1}$ Their comments can be summarized as follows: (1) concern with the safety of moderate hypothermic lower body circulatory arrest with selective cerebral perfusion in regard to protection of other organs, especially the spinal cord; (2) concern about the possibility of left vertebrobasilar ischemia in patients with 2-vessel selective cerebral perfusion; (3) concern 
that the circulatory arrest time might actually be shorter with the separated graft technique of arch vessel reconstruction compared with the island technique; (4) need for a bail-out technique when the arrest time becomes unexpectedly long; (5) concern about the reason for the high rate of re-exploration for bleeding in our series; and (6) concern that our strategy might be dangerous in complicated cases, such as acute aortic dissection type A, where hypothermic circulatory arrest duration is expected to be longer than 60 minutes.

First, this study was specially designed to answer several of these questions. No differences in complication rates and biologic parameters regarding specific organ protection were observed in the entire and matched study cohort in our study. The issue of paraplegia was also raised during the review process for this article. There was no difference of occurrence of paraplegia in the entire and matched study cohort or in the subanalysis in patients with acute aortic dissection type A. Indeed, the paraplegia rate was $18.2 \%$ in the moderate hypothermic arrest group and $0 \%$ in the deep hypothermic arrest group, and the $P$ value was .07 in the subanalysis of patients with hypothermic circulatory arrest of longer than 60 minutes. This value of $18.2 \%$ appear to be very high, but actually only 2 occurrences of this complication were counted in this subanalysis $(0 / 16$ in deep and $2 / 11$ in moderate hypothermic arrest), and we hesitate to conclude anything based on this small number of occurrences.

Second, in our series $23(6.1 \%)$ patients had strokes, but a specific left vertebrobasilar ischemia was detected in no patients. We have no experience with 3-vessel perfusion, including the left subclavian artery, and we have not performed preoperative cerebral angiography/magnetic resonance angiography on a routine basis to examine intracranial arterial communication. However, we consider from our own experience and reports from other institutions ${ }^{2,3}$ that 2-vessel perfusion represents a safe method.

Third, many diverse methods for arch reconstruction have been devised, ${ }^{4,5}$ but most surgeons stitch according to their own favorite technique, and usually they use only one method. Therefore it is difficult to say which method is faster. However, the question is beyond the focus of our study. As a conclusion of our article, our method should not be used for patients who require complex total arch replacement expected to require more than 60 minutes of circulatory arrest because our findings did not support that this method has no time limit. If circulatory arrest time would be less than 60 minutes with the separated graft technique in your institute, it appears that this higher-temperature strategy might not be a bad alternative for total arch repair.

Fourth, in our series $85 \%$ of patients with circulatory arrest for longer than 60 minutes received total arch replacement. We perform total arch replacement only in selected patients ( $23 \%$ in our study), but if needed, en bloc anastomosis is preferred. Therefore it is difficult to bail out in an unexpected situation requiring prolonged circulatory arrest. However, proper planning helps to avoid this situation.

Fifth, the reason for our relatively high re-exploration rate might be the high number of patients who received aortic root replacement (composite graft according to Bentall or aortic valve reconstruction according to David). Although there have been no data about it, we believe from our daily clinical observation that the combination of those complex aortic root procedures and hypothermic circulatory arrest results in a greater tendency toward bleeding as a result of a coagulation disorder plus long suture lines. In addition, the re-exploration rate for bleeding of less than $2 \%$ in arch surgery is surprisingly good, and we would like to congratulate you on your excellent results.

Sixth, as we described in our article, our data did not support that moderate hypothermic lower body arrest has no time limit, and it remains unclear whether it is safe beyond 60 minutes. However, our findings and a similar report recently published $^{6}$ suggest that deep $\left(<25^{\circ} \mathrm{C}\right)$ hypothermic circulatory arrest is not required in all patients.

Hiroyuki Kamiya, $M D^{a}$
Klaus Kallenbach, $M D^{a}$
Axel Haverich, $M D^{b}$
Matthias Karck, $M D^{a}$
Department of Cardiac Surgery
University of Heidelberg
Heidelberg, Germany
Department of Thoracic and Cardiovascular
Surgery
Hannover Medical School
Hannover, Germany

\section{References}

1. Kamiya H, Hagl C, Kropivnitskaya I, Bothig D, Kallenbach K, Khaladj N, et al. The safety of moderate hypothermic lower body circulatory arrest with selective cerebral perfusion: a propensity score analysis. $J$ Thorac Cardiovasc Surg. 2007;133:501-9.

2. Kazui T, Yamashita K, Washiyama N, Terada H, Bashar AH, Suzuki K, et al. Aortic arch replacement using selective cerebral perfusion. Ann Thorac Surg. 2007;83(suppl): S796-8.

3. Di Eusanio M, Wesselink RM, Morshuis WJ, Dossche KM, Schepens MA. Deep hypothermic circulatory arrest and antegrade selective cerebral perfusion during ascending aortahemiarch replacement: a retrospective comparative study. J Thorac Cardiovasc Surg. 2003;125:849-54.

4. Spielvogel D, Etz CD, Silovitz D, Lansman SL, Griepp RB. Aortic arch replacement with a trifurcated graft. Ann Thorac Surg. 2007; 83(suppl):S791-5.

5. Kouchoukos NT, Mauney MC, Masetti $P$, Castner CF. Single-stage repair of extensive thoracic aortic aneurysms: experience with the arch-first technique and bilateral anterior thoracotomy. J Thorac Cardiovasc Surg. 2004;128:669-76.

6. Pacini D, Leone A, Di Marco L, Marsilli D, Sobaih F, Turci S, et al. Antegrade selective cerebral perfusion in thoracic aorta surgery: safety of moderate hypothermia. Eur J Cardiothorac Surg. 2007;31:618-22.

doi:10.1016/j.jtcvs.2007.04.075 